\title{
Gram positive bacterial infections in immunocompromised patients with HIV infection
}

\author{
Andreea Cristina Stoian ${ }^{1,2^{*}}$, Florentina Dumitrescu ${ }^{1,2}$, Irina Niculescu ${ }^{1,3}$, Cristina locu ${ }^{2}$, Liliana Marinescu2, \\ Mariana Stănescu², Oana Bădescu², Georgeta Rodica Stoian ${ }^{3}$ \\ From The 9th Edition of the Scientific Days of the National Institute for Infectious Diseases Prof Dr Matei Bals \\ Bucharest, Romania. 23-25 October 2013
}

\section{Background}

We aimed to perform microbiological analysis of Gram positive infections in patients infected with HIV (PIH).

\section{Methods}

We performed a retrospective and compared study, between 01 January 2007 - 31 December 2010, in the Infectious Diseases Hospital of Craiova, on two groups of adults patients (Px): group A - 114 PIH and group B 1442 Px non HIV, which had been diagnosed with nontuberculosis bacterial infections (BI) with established etiology. For each group we analyzed the incidence, clinical spectrum, etiology and antibiotic susceptibility phenotype of Gram positive infections (GPI). For the statistical analysis we used the Fischer test; threshold values are statistically significant for $\mathrm{p}<0.05$ and relative risk $(\mathrm{RR})>2$.

\section{Results}

Incidence: group A vs. group B: BI-114 PIH (22.66\%) vs. $1442 \mathrm{Px}(8.7 \%)$ ( $\mathrm{p}=0.000, \mathrm{RR}=17.23)$, GPI-59 (51.75\%) vs. $378(26.21 \%)(\mathrm{p}<0.0001) ; S$ aureus -31 PIH $(27.19 \%)$ vs. $58 \mathrm{Px}(4.92 \%)(\mathrm{p}=0.000 ; \mathrm{RR}=6.42), S$ pneumoniae -24 PIH (21.05\%) vs. 234 Px (16.22\%) ( $\mathrm{p}=0.01 ; \mathrm{RR}=2.79)$, Enterococcus spp. - 2 PIH (1.75\%) vs. 7 Px (0.49\%) $(\mathrm{p}<0.05)$, S pyogenes - 2 PIH $(1.75 \%)$ vs. $77 \mathrm{Px}(5.33 \%)$ $(\mathrm{p}<0.05)$ and $S$ viridans $-2 \mathrm{Px}(0.14 \%)$ only in group B. The clinical spectrum was dominated by lower respiratory tract infections: 29 PIH (49.15\%) vs. 237 Px (69.09\%) $(\mathrm{p}=0.004)$. Sensitivity to antibiotics: $S$ pneumoniae, group A vs. group B: teicoplanin, linezolid $24(100 \%)$ vs. 234 $(100 \%)(\mathrm{p}<0.05)$, moxifloxacin, $24(100 \%)$ vs. 228 (97.43\%) $(\mathrm{p}<0.05)$, vancomycin $24(100 \%)$ vs. $228(97.43 \%)(\mathrm{p}<0.05)$, erythromycin $-18(75 \%)$ vs. $166(70.94 \%)(\mathrm{p}<0.05)$, co-trimoxazole $9(37.5 \%)$ vs. $119(50.84 \%)(\mathrm{p}<0.05)$, penicillin $10(41.62 \%)$ vs. $92(39.31 \%)(\mathrm{p}<0.05)$, ceftriaxone, $21(87.5 \%)$ vs. $198(84.61 \%)$ ( $<<0.05)$, rifampicin $18(75 \%)$ vs. $217(92.73 \%)(\mathrm{p}=0.000)$ antibiotic sensitivity of $S$ aureus, group A vs. group B (41 strains tested): oxacillin $24(77.41 \%)$ vs. $33(80.48 \%)(\mathrm{p}>0.05)$ erythromycin, $13(41.93 \%)$ vs. $21(51.21 \%)(\mathrm{p}<0.05)$, co-trimoxazole $8(25.80 \%)$ vs. 29 (70.73\%) (p<0.05), amikacin $29(93.54 \%)$ vs. $38(92.68 \%)(\mathrm{p}<0.05)$, vancomycin $31(100 \%)$ vs. $39(95.12 \%)(\mathrm{p}<0.05)$, linezolid $31(100 \%)$ vs. $41(100 \%)$, clindamycin $29(93.54 \%)$ vs. $38(92.68 \%)(\mathrm{p}<0.05)$.

\section{Conclusion}

Gram positive infections are more common in PIH versus Px non-HIV; the clinical spectrum is dominated by acute respiratory tract infections, regardless of HIV status. HIV infection was associated with high risk of resistance of $S$ pneumoniae to co-trimoxazole, rifampicin and of $S$ aureus to co-trimoxazole.

\section{Authors' details \\ "University of Medicine and Pharmacy Craiova, Romania. "Victor Babeş" Clinical Hospital of Infectious Diseases and Pneumology, Craiova, Romania. \\ 3"Dr. Vlăescu" Medical Center, Craiova, Romania.}

Published: 16 December 2013

doi:10.1186/1471-2334-13-S1-P30

Cite this article as: Stoian et al:: Gram positive bacterial infections in immunocompromised patients with HIV infection. BMC Infectious Diseases 2013 13(Suppl 1):P30.

* Correspondence: andreea_plr@yahoo.com

'University of Medicine and Pharmacy Craiova, Romania

Full list of author information is available at the end of the article

( 2013 Stoian et al; licensee BioMed Central Ltd. This is an Open Access article distributed under the terms of the Creative Commons 